\title{
Predicting Nanocrystallites Development in Cement Pastes
}

\author{
A. Feylessoufi \\ UnivEvry, University of Paris Saclay, F-91025 Evry, France \\ Email: a.feylessoufi@physique.univ-evry.fr
}

How to cite this paper: Feylessoufi, A. (2018) Predicting Nanocrystallites Development in Cement Pastes. Open Journal of Civil Engineering, 8, 27-40.

https://doi.org/10.4236/ojce.2018.81003

Received: December 20, 2017

Accepted: March 4, 2018

Published: March 7, 2018

Copyright $\odot 2018$ by author and Scientific Research Publishing Inc. This work is licensed under the Creative Commons Attribution-NonCommercial International License (CC BY-NC 4.0). http://creativecommons.org/licenses/by-nc/4.0/ (c) (i) \&) Open Access

\begin{abstract}
Cement nanocrystallites constitute the binding phase in concrete, a material that has been around for more than two thousand years and remains the most widely used of manufactured materials. Thanks to their size, their disordered nature, their reprecipitation after combination with water, and their rapid evolution when the concrete sets, these nanostructures have only been subjected to careful investigation quite recently. Nanotechnology is now able to control their formation and exploit their evolution (shrinking and swelling) during the setting phase to produce a concrete with a strength and ductility close to those of steels. Furthermore, the analysis of basic nanoscopic reactions occurring during setting, and their modification by polymer additives acting at the interfaces, numerical modelling techniques are potentially able to predict big evolutions and properties of nanocrystallites. Here we discuss the future of these nanocrystallites in new applications.
\end{abstract}

\section{Keywords}

Concrete, Cement, Hydration, Nanocrystallite, Nanomaterial

\section{A Very Surprising Material}

Cementitious materials, known mainly in the form of concrete, are without doubt the oldest and the most widely used manufactured materials in the world, with more than a tonne produced per year and per person. They comprise a granular assembly bound together by a nanostructured matrix, also called the binding phase, which is the common feature of all such materials.

In fact, this nanostructured matrix is made up of hydrated chunks, each measuring a few tens of nanometers. These are hydrated calcium silicates, but often also hydrated calcium aluminosilicates or ferroaluminosilicates, in proportions that are non-stoichiometric with respect to the oxide content "Figure 1". 


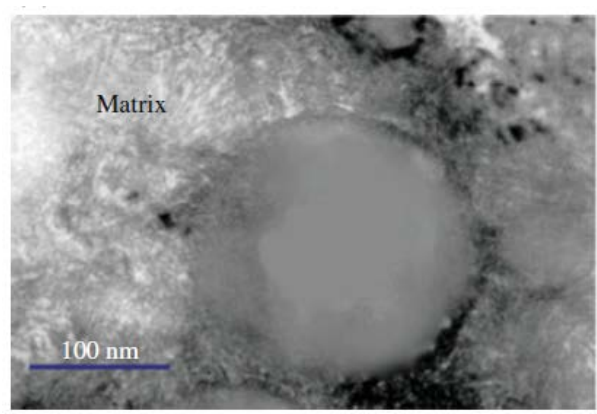

(a)

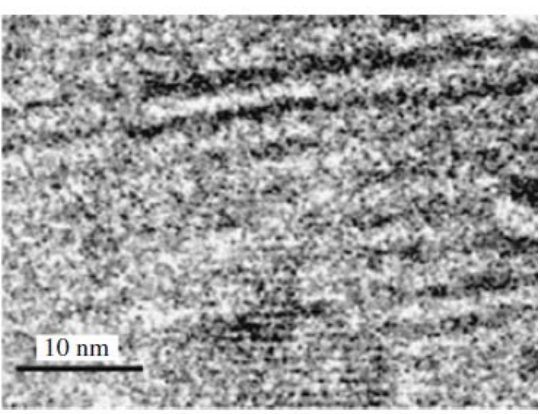

(b)

Figure 1. Nanocrystallites in the cement matrix. Transmission electron microscope images. (a) On the scale of the cement matrix and (b) on the scale of the nanocrystallites, showing their poorly ordered structure. From [1], @2001 Springer New York LLC, reproduced with kind permission.

These oxides $\left(\mathrm{CaO}, \mathrm{SiO}_{2}, \mathrm{Al}_{2} \mathrm{O}_{3}, \mathrm{Fe}_{2} \mathrm{O}_{3}\right.$, etc. $)$ are already in the cement grain in crystallised form. Upon contact with water, part of these oxides dissolves, then diffuses under the strong concentration gradients and precipitates out again in the form of nanometric hydrates, which are also called nanocrystallites owing to their size and the fact that they are poorly ordered, midway between the amorphous and crystalline phases [1].

As for any composite structure, it is this matrix that plays the determining role in the mechanical behaviour of the cementitious material. While the setting is under way, which may take a few hours or a few tens of hours, the cementitious material goes from a quasi-Newtonian liquid state to a viscoplastic state, then gradually acquires a visco-elasto-plastic behaviour, until finally it becomes a solid that is both very rigid, with Young's modulus as high as a few tens of $\mathrm{GPa}$, and very strong, with a compressive yield stress between about ten and a few hundred $\mathrm{MPa}$, depending on the formulation.

It is the exceptional reactivity of this nanostructured matrix, and at room temperature, hence very economical, which is really the strong point of these cementitious materials, because one can control this or that property either at the prefabrication stage or at the building site, depending on the use which the material will be put to. Moreover, its very basic $\mathrm{pH}$ favours the use of passive or active reinforcement steel. However, if the setting stage is not properly controlled, the cement matrix can quickly become of very poor quality, exhibiting various pathologies such as carbonatation, sulfation, or the alkali reaction, which may affect both aesthetics and durability. It is also through the matrix that radioactive atoms can penetrate concrete when it plays the role of barrier against radioactivity produced in nuclear power stations. And it is once again the matrix that is responsible in cases of shrinkage and consequent crack formation, with a possible loss of structural integrity.

\section{The Roman's Were Here}

It was the Romans who discovered cement serendipitously around the village of 
Pozzuoli near Naples in Italy. The place has given its name to the hydration of cement, which is still called the pozzolanic reaction. What they found was a powder which, when it came into contact with water, turned into an artificial stone. In fact, it consisted of ash thrown out of the volcano. Naturally, the latter was able to boil up the essential ingredients of cement, which are limestone and clay.

One of the most remarkable edifices in which the Romans used concrete was the Pont du Gard, built near Nîmes in the south of France between 50 and 60 AD. A mortar made from sand and pozzolanic powder (an ancestor of concrete) was used as binder in this stone construction, some time before the famous dome of the Pantheon in Rome, proving that the Romans were the first to produce and use this material on an industrial scale "Figure 2". However, the recipe for making it was lost in the Middle Ages.

\section{Late Rediscovery and a Burst of Development}

Cement was reinvented at the beginning of the nineteenth century by the English bricklayer and businessman Joseph Aspdin who, in 1824, began to manufacture "Portland" cement, referring to it as artificial stone and naming it by analogy with the Portland stone, an oolitic limestone quarried on the Isle of Portland in Dorset. Its composition differed only slightly from the product of the same name today. In 1855, the French engineer Louis Vicat built the bridge in the Jardin des Plantes in Grenoble, the world's first poured concrete construction. But it was only in 1887 that the French chemist Henri Le Châtelier devised the theory of cement hydraulicity, i.e., the body of knowledge that elucidates the nature of hydrates, until then unexplained. Cement was thereafter understood to be a salt with the exceptional property of being water stable! To illustrate the rapid development of cementitious materials during the second half of the twentieth century, it is useful to consider the evolution of one of its properties, namely its compressive strength, i.e., the maximum stress a material can sustain without rupture under a compression test. Up until the 1930s, the standard compressive
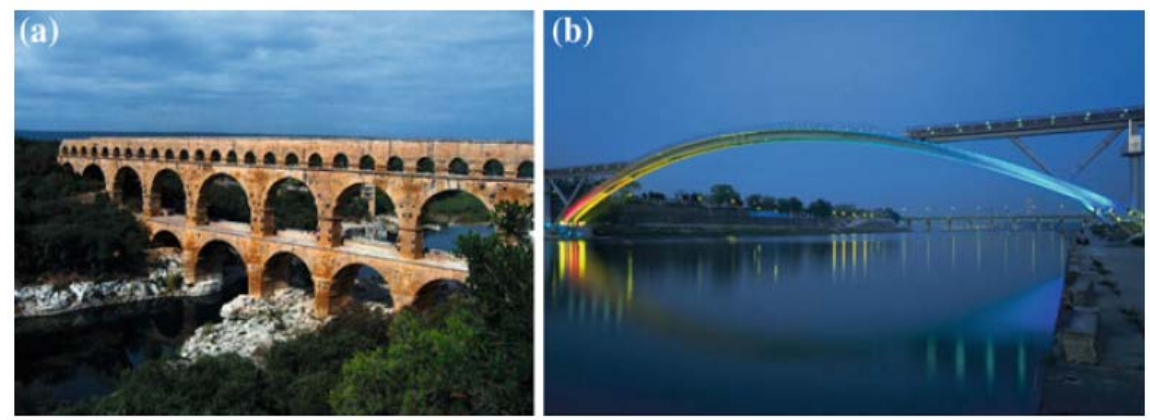

Figure 2. Two thousand years went by between the constructions of these concrete edifices. Left (a) The Pont du Gard in France (photo credit Emanuele), assembled with a mortar using pozzolanic ash. Right (b) The Footbridge of Peace in Seoul, built with ultra-high performance concrete (photo credit Philippe Ruault, Bouygues). 
strength of concretes was $20 \mathrm{MPa}$. It reached $40 \mathrm{MPa}$ in the $1960 \mathrm{~s}$, then $90 \mathrm{MPa}$ in the 1970s with high-performance concretes (HPC), and finally $120 \mathrm{MPa}$ with very high-performance concretes (VHPC) at the end of the 1980s.

Indeed, up until the 1930s, it was known that increasing the amount of mix water for a given mass of cement reduced the compressive strength of the resulting concrete, because the water associating with the cement in the hydrates gave way to a certain porosity in the material, and the strength of the concrete was thereby diminished in the same proportion. For the engineer, the amount of mix water should be just enough to obtain the rheology required for the application to hand. To reduce the amount of water needed, blood can also be used. This is a natural surfactant, i.e., a natural wetting agent, allowing better wetting of the cement grains for a given amount of water, and hence producing better hydration of the cement. So, off to the slaughterhouse! In the 1960s and 1970s, sulfonated industrial surfactants were commonly used, including sulfonated naphthalene condensates and naphthalene-formaldehyde condensates or sulfonated melamine condensates and melamine-formaldehyde condensates. This made the concrete much stronger (HPC) and/or more fluid for a given amount of water (self-compacting or self-consolidating concretes). Fresh concrete could be pumped to a height of over $100 \mathrm{~m}$, as for the construction of the Arche de la Défense in Paris, with a considerable gain in productivity. Note that the word "performance" is used in preference to 'strength', because the issue here is not just optimization of the strength. Other aspects of the performance are important, such as the rheological properties or durability, and these can be optimized through different but similar reformulations.

\section{Ultra-High Performance Concretes}

A considerable technological leap occurred during the 1990s and 2000s. Industrial levels of compressive strength reached values above $800 \mathrm{MPa}$ with the ultra-high performance concretes (UHPC). At the beginning of the 1990s, university research centers began to advocate the use of large amounts of polymers (up to $20 \%$ ) to produce macro defect free (MDF) concretes, i.e., without macroscopic defects, using the simple idea of filling any residual porosity with hydroxypropyl methylcelluloses (HPMC) and endowing the composite with a certain ductility. However, despite their great strength, these concretes lost out with regard to durability because the polymer had to be water soluble in order to be incorporated in the mix, but would subsequently lose its properties under the effects of humidity. In addition, preparation of these materials required a process associating kneading and calendering which proved too complex and too costly, and hence was incompatible with industrial applications. This approach was quickly dropped from the agenda. In the mid-1990s, thanks to the efforts of a visionary French industrialist who was scientific director at Bouygues, considerable resources were devoted to the development of new concretes. Several French research projects under the name Saut technologique or Réactif, and Brite-Euram 
European projects bringing together a network of industrial companies, such as Lafarge, Rhodia, etc., and about twenty research centers set out to develop the bétons Pierre Richard or bétons de poudres réactives (BPR), named after their main advocate and also known as reactive powder concretes (RPC), later commercialised under the name of Ductal. These concretes, which achieved strengths from $300 \mathrm{MPa}$ to more than $800 \mathrm{MPa}$, were set to revolutionise the rules of architectural design. They were clearly beginning to compete with steels, having similar strengths, a specific mass three times lower, and a cost ten times lower! One might think that, with concretes ten times stronger, the mass of concrete used would be ten times less, but that would be forgetting that $80 \%$ of the strength of a bridge is used only to support its own weight! Much lighter and more aesthetic architectures thus become possible, like the Sherbrooke Footbridge in Quebec and the Footbridge of Peace in Seoul "Figure 2", where the apron of the bridge is only $3 \mathrm{~cm}$ thick!

\section{Toward Nanometric Sizes}

Without reducing the size and fineness of the pore network, it would have been illusory to try to improve performance and strength by focusing on nanocrystallites. Indeed, fracture mechanics teaches us that strengths are inversely proportional to the square root of the typical size of a characteristic defect, and the defects here are the pores. There was thus no way of making further improvements while the pores remained at micrometric sizes. It was therefore essential to achieve nanometric pore sizes, without forgetting that, if the grains are too closely packed, the hydration reaction will lead precisely to a localization of shrinkage, causing cracks to form. The challenge was taken up on the basis of two in principle contradictory ideas. The first was optimal filling of intergrain gaps using a decreasing granulometry, down to nanometric size, and an Apollonian packing. This goalwas achieved rather cheaply using colloidal silica with optimal sieving, from about ten nanometers to several hundred nanometers. The silica was available as a waste product from the silicon and steel industries, but today this precious waste product is no longer available in sufficient quantities, so it has to be made especially for the cement manufacturers!

The other idea was grain loosening, i.e., separating the grain sizes and ensuring that the shrinkage which occurs when the concrete sets is uniformly distributed throughout the material, without localisation. Indeed, any localisation would lead to harmful microcracks, quite the opposite of the desired effect. In addition, grain loosening facilitated the flow and spread of the fresh concrete into the required volumes by preventing the grains from jamming up! However, the use of nanoscale colloidal silica grains considerably increased the specific surface area and hence also the amount of water required. This problem was tackled using highly efficient new generation surfactants, viz., methacrylic polymers with long neutral chains of ethylene polyoxide. The problem there was that, at high concentrations, these polymers acted at the water-cement interface to per- 
turb the hydrate formation mechanisms. A perfect balance had therefore to be found between the grain packing, grain loosening, and the proportion of polymers acting at the interfaces.

\section{More Rigid Nanocrystallites}

The introduction of colloidal silica into the formulation had some quite unexpected results. Forming by solid condensation and strictly spherical, they provided excellent lubrication during mixing and very good rheology in the fresh concrete. Furthermore, they diffused within the nanocrystallites, thereby reducing their $\mathrm{Ca} / \mathrm{Si}$ ratio to values less than unity. In such proportions, their elastic moduli in the matrix were higher and close to those of the non-hydrated cement and silica grains remaining in the matrix, so that, during mechanical loading, there was a better distribution of stresses with less gradation from one phase to the other.

\section{Progress in Nanocrystallite Thermodynamics}

Another property of nanocrystallites with a low ratio of $\mathrm{Ca}$ to $\mathrm{Si}$ was their improvement in heat treatments at the prefabrication stage. Heat treatments of concretes had previously been poorly regarded because conventional hydrates evolve toward hydrates with inferior mechanical properties. However, the situation turned out to be quite the opposite for hydrates made from nanocrystallites with high silica content, because they transform into nanocrystallites with excellent mechanical quality, such as xonotlite or gyrolite. Further studies carried out with university research centers led to the specification of a heat treatment that perfectly controlled the thermodynamics involved in the formation of these phases [2], and this had industrial spinoffs for the heat treatment of prefabricated concretes.

\section{Better Resistance to Wear and Tear}

This is how concretes are obtained with nanoscopic pore networks. The typical pore size as found by high resolution porosimetry [3] for ultra-high performance concretes was only two or three nanometers "Figure 3". But apart from strength, there are other advantages in having such a fine nanometric pore structure. The first is durability, because pathogenic agents, or even radioactive atoms, are no longer able to enter such very small pores. This type of concrete has thus been used to store category B radioactive waste. The second advantage is resistance to freeze-thaw cycles. Resistance to freezing is generally the weak point of conventional concretes, because residual water in the capillary pores tends to freeze when temperatures are very cold and break the concrete from within. But inside a pore that is only two or three nanometers across, the water is bound to hydrates and does not begin to freeze until the temperature falls below $-20^{\circ} \mathrm{C}$, a considerable advantage for concretes to be used in cold climates. 


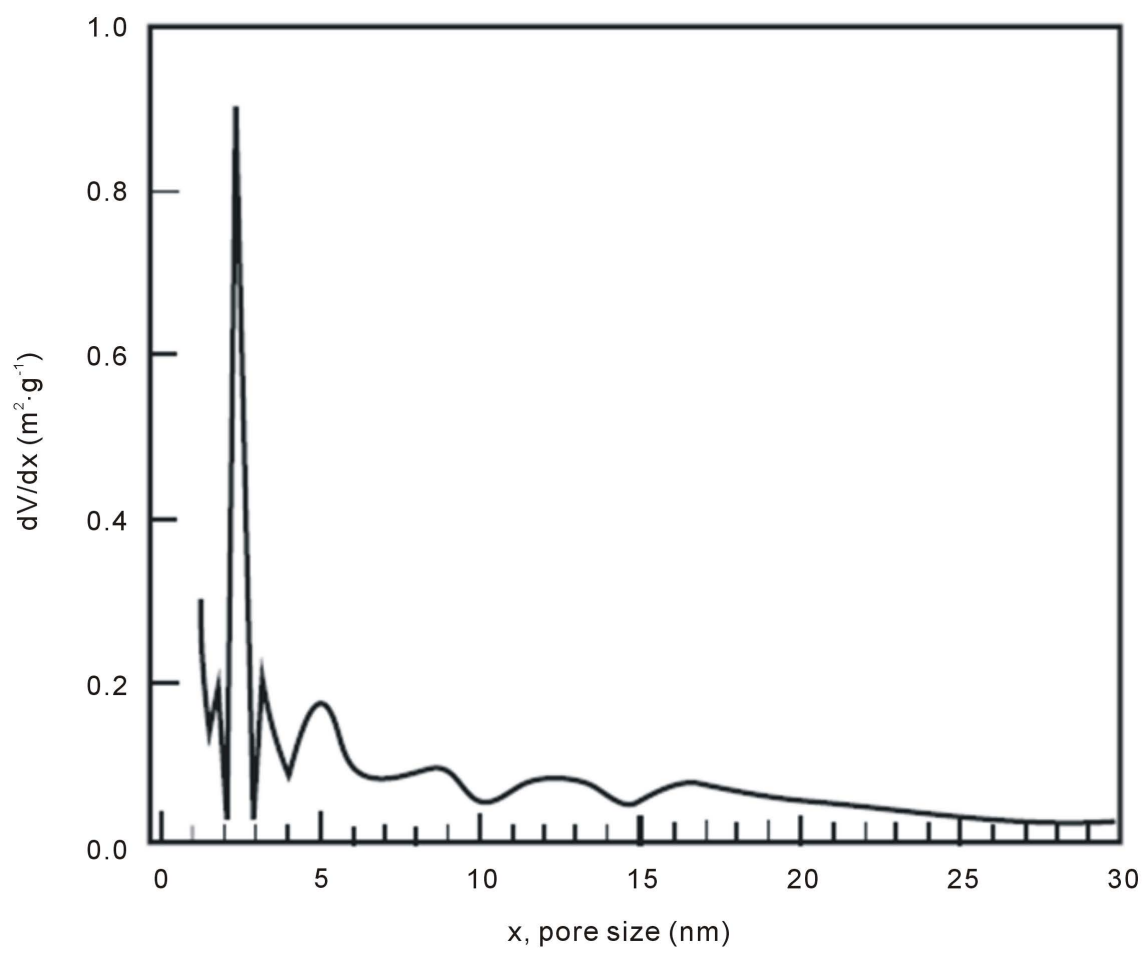

Figure 3. Modern concretes are characterized by a predominantly nanoscopic porosity, which increases strength and makes it difficult for pathogenic gents to penetrate. Here the specific volume occupied per pore radius is analyzed by high resolution nitrogen porosimetry. The predominant pore size lies between two and three nanometers. From [3], (C)2001 Elsevier.

\section{The Beginning of the Twenty-First Century: A Clear Future}

The development of experimental techniques and modelling at the end of the twentieth century and the beginning of the twenty-first has led to a better understanding of the genesis, aggregation, and structuring of the nanocrystallites during setting, as well as the gradual development of their textural and physical-chemical-mechanical properties "Figure 4". Whereas all the relevant mechanisms used to be encompassed as one under the general term 'setting', we can now identify the chemical and topological mechanisms occurring during this process [4] [5] [6]. We have thus entered into a phase where the aim is no longer to improve the product, but to develop a genuine ability to engineer these nanocrystallites, targeting specific properties.

The most effective methods then used synchrotron X-ray radiation [4], e.g., at the European Synchrotron Radiation Facility in Grenoble, or very intense neutron beams, e.g., at the Laue-Langevin Institute in Grenoble, to identify the hydrates. Indeed, using conventional X-ray diffraction techniques in the laboratory, it was never possible to identify the hydrated calcium silicate nanocrystallites: they were too small (ten nanometers or so) and they were very poorly ordered. In addition, exposures had to be much too long, around ten hours, so it was 


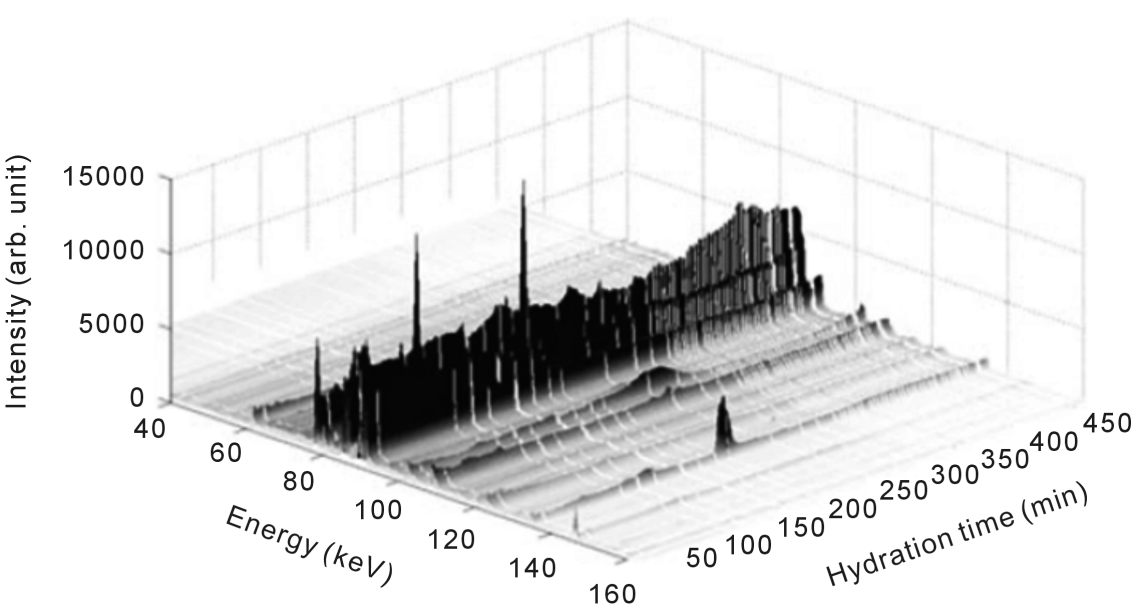

Figure 4. Synchrotron radiation can be used to obtain almost instantaneous X-ray diffraction patterns as hydration proceeds [4]. The nanocrystallites, often poorly ordered, appearing and disappearing over periods of ten seconds or so, can be distinguished and analyzed, something that was quite impossible using laboratory $\mathrm{X}$ rays about a million times less intense!

impossible to monitor the development of these nanocrystallites during the setting process. With fluxes up to a million times more intense than laboratory $\mathrm{X}$ rays, the synchrotron source made it possible to detect the nanocrystallites as they formed and disappeared on time scales of around ten minutes ("Figure 4").

Other spectroscopic techniques using nuclear magnetic resonance (NMR), silicon-29 NMR or aluminium-27 NMR, provided a better analysis of the inorganic polymerisation of the nanocrystallite networks, while proton NMR [5] was used to characterize the bonds between the nanocrystallites and water and the incorporation of water molecules into the nanocrystallites during hydration "Figure 5". Imaging techniques such as ultra-high resolution transmission electron microscopy [1] have made it possible to measure lattice spacings within highly disordered crystallites. Atomic force microscopy was unable to reconstruct a clear image owing to the poor ordering of the nanocrystallites, but it proved useful for measuring surface and van der Waals forces on the level of the nanocrystallites.

The methods of high-resolution porosimetry, in near-equilibrium, using molecules with different shapes and properties, are crucial for measuring the size and distribution of nanopores, and even for producing an image of their shape. This in turn made it possible to model mechanisms of shrinkage and permeability with respect to pathogens.

Setting is an exothermic reaction whose progress can be measured in various ways. For a given sample of ultra-high performance concrete, two methods are considered here [6]: isothermal calorimetry and shear wave ultrasonic testing, both highly sensitive to the structuring of the cementitious matter. Isothermal calorimetry tells us the dissipated power per unit mass of concrete "Figure $6(a)$ ". As soon as the water has been introduced, heat power is emitted from the 


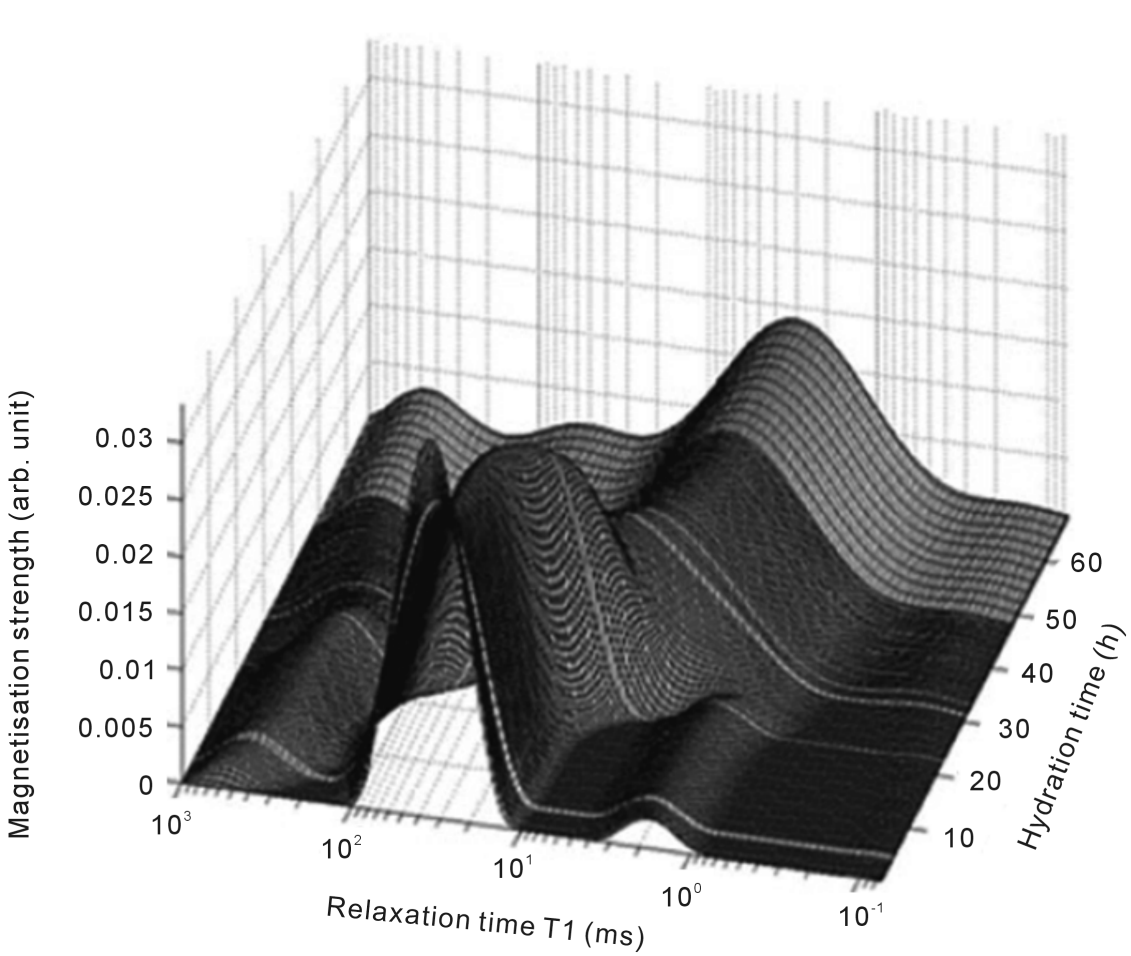

Figure 5. After excitation in a magnetic field, proton spin moments undergo exponential relaxation until they recover the equilibrium magnetization. This relaxation, known as spin-lattice relaxation, has a characteristic time denoted by $\mathrm{T} 1$, which depends on the level of bonding of the protons in the water molecule. The dependence of the relaxation time $\mathrm{T} 1$ on the extent of hydration informs us, on the scale of a few angstrom units, about the bonds between the water molecules and the nanocrystallites, until the former are entirely incorporated, thus forming cement hydrates [5].

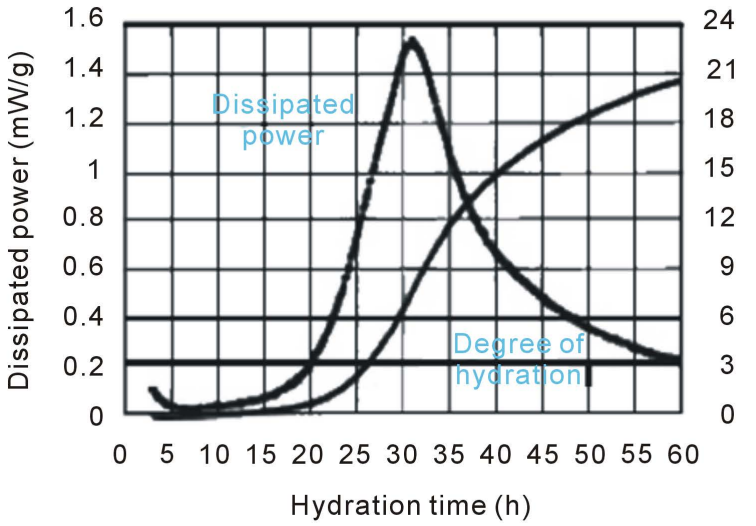

(a)

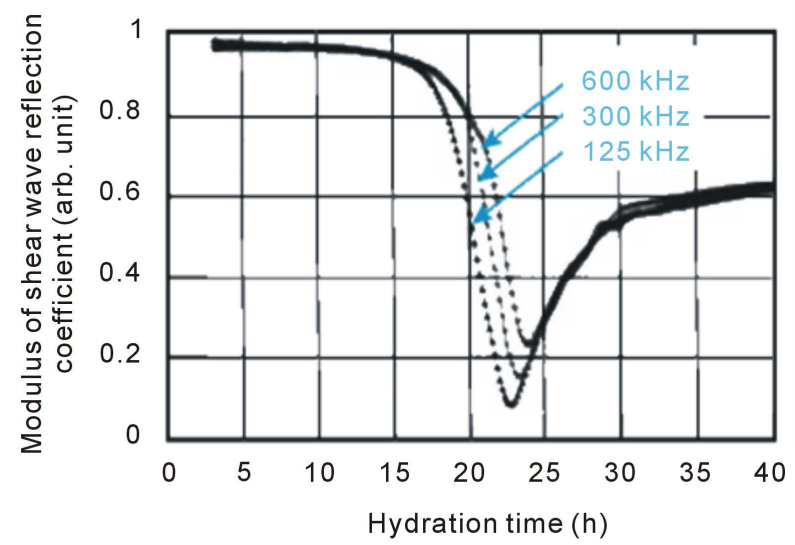

(b)

Figure 6. (a) Dissipated power per unit mass of concrete as determined by isothermal calorimetry. (b) Shear wave reflection coefficient as determined by ultrasonic testing. Adapted from [6], oElsevier.

hydration of tricalcium aluminates, these being one of the components of the cement. This is followed by a dormant period which may last for several hours, whereupon the dissipated power climbs to a maximum. The concrete is then 
considered to have set. On the building site, it is at this moment that formwork is removed. However, hydration continues for several months. The integral of the power curve "Figure 6(a)" indicates the progress of the reaction. The degree of hydration corresponds to the heat emitted since the beginning of the setting process divided by the heat that will have been emitted when the whole sample has been hydrated. Note that, for modern ultrahigh performance concretes, the cement is never fully hydrated. The degree of hydration never exceeds $20 \%$ $25 \%$. The rest of the cement remains available and, in the case of nano or microcracking it can combine with penetrated water or water provided by humidity to mend such cracks. Shear (or transverse) wave ultrasonic testing also tells us how far setting has proceeded by revealing the ordering of the cementitious nanocrystallites "Figure 6(b)". In the early stages, there is no connection between the nanocrystallites, which means that the transmitted shear waves cannot cross the sample. The shear waves are thus reflected in their entirety and the modulus of the reflection coefficient is equal to one. As hydration proceeds, the matter percolates, leading to a decrease in this modulus, then orders itself into clusters of different sizes. This explains the dispersion of the reflection curves at different frequencies until they come back together again, indicating that the clusters have joined up into a single structure.

However, it was the advent of high resolution ultrasound spectroscopy [6] that did most to improve our understanding of the mechanisms of percolation and aggregation in the evolving phases by providing precise information about the elastic moduli of the developing nanocrystallites "Figure 7". During the 2000s, this resulted in the first attempts to engineer the nanocrystallites. Formulations able to develop networks of nanocrystallites that could improve performance by blocking harmful shrinkage, the cause of microcrack formation, were patented. Other direct results from this technique were formulations facilitating extrusion forming of cement nanomaterials. In parallel with the analysis of the basic nanoscopic reactions occurring during setting, and their modification by tiny amounts of polymer additives acting at the interfaces, numerical modelling techniques known as cellular automaton models have been developed and are now potentially able to predict the evolution of nanocrystallites in all their complexity [7] [8] [9]. However, in order to produce a genuine prediction, we must actually be able to model the evolution of the nanocrystallites in all their complexity, and we are a long way from being able to do that in practice, because not all the reactions occurring during setting are in fact known for the moment and because the computations are still too heavy.

\section{The Scientific Challenge}

The challenge here is to improve the nanocrystallites for specific needs, develop ways to engineer them, and 'program' their evolution during hydration in such a way as to control their properties at various stages. However, our knowledge in this respect is extremely limited, and incomparably inferior to what is known in 


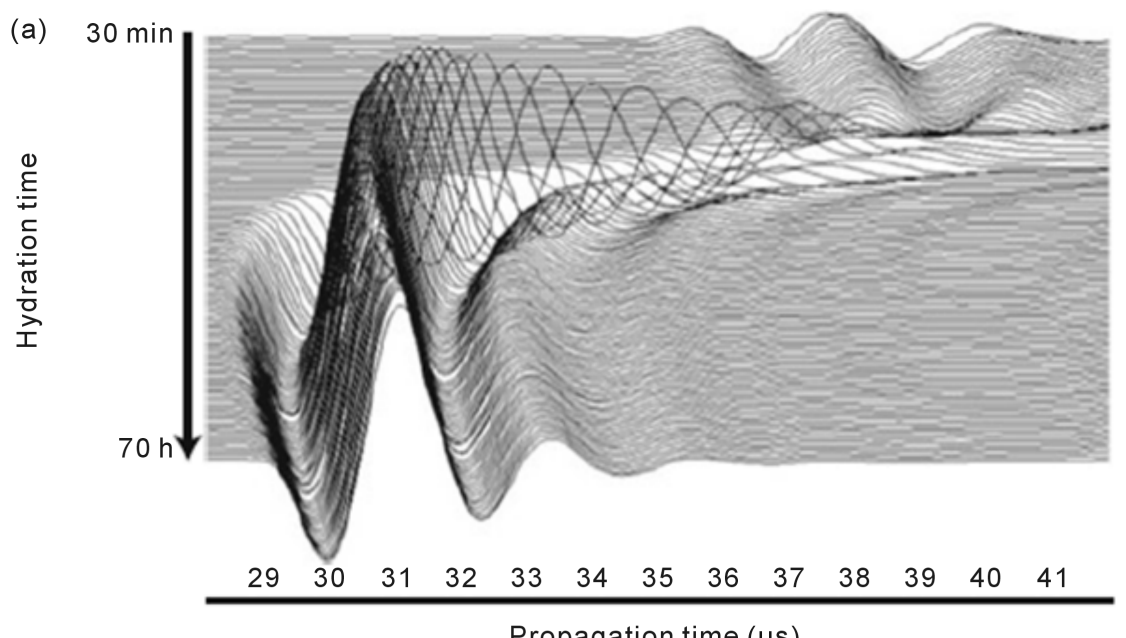

(b)

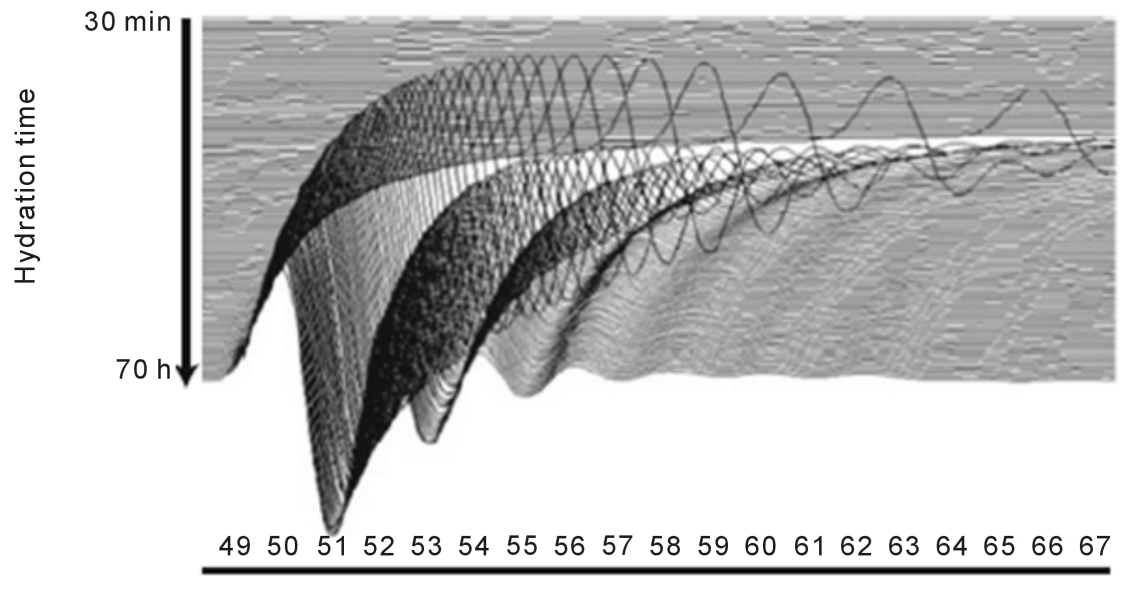

Propagation time $(\mu s)$

Figure 7. Signals corresponding to compression waves (longitudinal component) (a) and shear waves (transverse component) (b) after different hydration times. The speed of propagation obtained by measuring the propagation time of acoustic compression and shear waves in a sample at different frequencies can be used to deduce the viscoelastic moduli of the developing crystallites. Adapted from [6], (อ) Elsevier.

solid state physics, metallurgy, or biology for the development of nanomaterials. The local thermodynamic conditions of deposition and accumulation of nanocrystallites remains to be determined, and so too are the causes of local fluctuations in the composition and adhesive strength observed by electron microscopy and near-field microscopy.

It also remains to understand the morphological, structural, and crystallochemical development of the nanocrystallites if we are to be able to modify the surface properties and cohesive properties of the assemblies. This will require state-of-the-art knowledge of surface chemistry and crystal growth, because the growth of calcium silicate nanocrystallites must be optimized to obtain the most cohesive interface possible with the limestone or the slag.

Nanocrystallite assemblies are also controlled on the mesoscale. Intermediate 
levels of organization over lengths greater than the micrometer would appear to have been observed between the nanocrystallite sheet and the continuous binding matrix [10] [11] [12]. They look like stacks of sheets measuring a few tens of nanometers laterally and a few nanometers in thickness. The question is whether an interstitial solution could modify their size, shape, and assembly. In plaster, the growth of hydrates (gypsum) is controlled by adding organic molecules which selectively modify the surface energies of the different crystal faces of the gypsum when adsorbed. One can therefore consider applying this approach to cement nanocrystallites, especially now that it can be supported by molecular modelling calculations.

Another possibility for modifying the mechanical properties of the assemblies would be to change the topology of the cement nanocrystallites, which are generally two-dimensional, by in situ synthesis of mixed hydrates of silicon and aluminium, which are three-dimensional. Industrial development would be achieved by the synthesis and control of protozeolitic structures. We must also relate the hydromechanical properties to the morphology of the cementitious material on all the scales just mentioned. There is a long way to go, but it is nevertheless worth consideration.

\section{The Industrial Challenge}

The main industrial challenge is to convince the decision-makers that these new nanomaterials are economically advantageous, recalling that ultra-high performance concretes have been advocated for their mechanical strength and their ability to meet the technical challenges in an economically viable way. Their exceptional durability, their resistance in aggressive environments, the fact that no maintenance is necessary, and the ease with which they can be applied are all arguments justifying their use. Their early age rheology has seen them pumped to a world record height of $606 \mathrm{~m}$, thereby avoiding the need to transport prefabricated structures to this altogether exceptional height. The construction of the Burdj Khalifa in Dubai, the tallest building in the world, culminating at $830 \mathrm{~m}$, is a recent demonstration of the economic viability of these "nanoconcretes". A tower more than a kilometer high is under study. Energy could be generated by exploiting the air flow produced by the temperature difference between the top and bottom! For such constructions, absence of maintenance is a decisive economic argument when the comparison is made with metal structures. Nanoconcretes are the only materials able to resist both freeze-thaw cycles and pathogenic carbonatation and sulfation agents without the need for maintenance. When titanium dioxide $\left(\mathrm{TiO}_{2}\right)$ is incorporated in very small amounts, they even become self-cleaning under the Sun's UV radiation, displaying a smooth and aesthetic surface, and above all they are highly economical for the customer.

A further advantage of nanoconcretes is that they are very light for a given strength, in particular when compared with steel! It is a common mistake to assume that concrete is heavy. Its density of $2.0-2.6 \mathrm{t} / \mathrm{m}^{3}$ is lower than the density 
of aluminium. There has even been a suggestion to use nanoconcretes to armour military helicopters! This low density can procure a considerable saving in material, and the cost of the material represents around a quarter of the cost of a construction, while profit margins are only a few percent in major building projects. The contractor or the owner can thus double their profit by using nanoconcrete. Hence the greatest challenge lies outside the field of construction, industrialists wishing to set up in markets where they are currently absent. The aim is to exploit all the properties offered by the engineering of "customised" nanocrystallites and to substitute nanoconcretes for metal materials or high-resistance polymers by commercializing premixes, i.e., optimized dry mixtures comprising cement, polymer additives modifying the setting mechanisms, sand, and ground quartz. This aim seeks to exploit the visco-elasto-plastic properties during setting (at room temperature) and the design of forming machines adapted to suit the nanoconcretes. The profits expected in these markets are truly enormous because the forming processes for the metal alloys currently used must be carried out at high temperatures, whence they are energy costly, and they also require considerable investment in the production unit.

Finally, nanoconcretes have some environmental advantages, an important factor in the eyes of the authorities. In addition to their low energy consumption during manufacture ( $1.4 \mathrm{GJ} / \mathrm{t}$ for concrete, compared with $30 \mathrm{GJ} / \mathrm{t}$ for steels) and their low greenhouse gas contributions $\left(\mathrm{CO}_{2}, \mathrm{SO}_{2}\right.$, and $\mathrm{NOx}$ : on average 147, 0.2, and $0.6 \mathrm{~kg} / \mathrm{t}$ for concrete, compared with more than 3000,3 , and $5 \mathrm{~kg} / \mathrm{t}$ for steels), they are easy to recycle because hydrated cements can simply be loaded into the cement oven to dehydrate them and recover the original cement [13].

\section{Acknowledgements}

This is to acknowledge that parts of this article are from a book chapter detailed below [14] from the same author, with kind permission of the editor. For more explications and analysis about mechanisms and about many remaining obstacles and for more developments particularly in university and industrial fields or in student training, one can refer to this book.

\section{References}

[1] Gatty, L., Bonnamy, S., Feylessoufi, A., Clinard, C., Richard, P. and Van Damme, H. (2001) A Transmission Electron Microscopy Study of Interfaces and Matrix Homogeneity in Ultra-High-Performance Cement-Based Materials. Journal of Materials Science, 36, 4013-4026. https://doi.org/10.1023/A:1017938725748

[2] Feylessoufi, A., Crespin, M., Dion, P., Bergaya, B., Van Damme, H. and Richard, P. (1997) Controlled Rate Thermal Treatment of Reactive Powder Concretes. Advanced Cement Based Materials, 6, 21-27. https://doi.org/10.1016/S1065-7355(97)90002-X

[3] Feylessoufi, F., Villieras, F., Michot, J.-L., De Donato, P., Cases, J.-M. and Richard, P. (1996) Water Environment and Nanostructural Network in a Reactive Powder Concrete. Cement and Concrete Composites, 18, 23-29. 
https://doi.org/10.1016/0958-9465(95)00036-4

[4] Soth, R., Feylessoufi, A. and Cassar, L. (2006) Early Age Hydration of Cement Pastes by Energy-Dispersive Synchrotron X-Ray Diffraction and Neutron Diffraction. 2nd Advanced Cementitious Materials Symposium (ACM06), 4-5 September 2006, Evry.

[5] Soth, R., Faure, P., Rodts, S. and Feylessoufi, A. (2006) Nuclear Magnetic Resonance and Ultrasonic Spectroscopy Investigation for Understanding Setting Mechanisms of a Modified Cement Paste. 2nd Advanced Cementitious Materials Symposium (ACM06), 4-5 September 2006, Evry.

[6] Feylessoufi, A., Cohen-Tenoudji, F., Morin, V. and Richard, R. (2001) Early Ages Shrinkage Mechanisms of Ultra-High-Performance Cement-Based Materials. Cement and Concrete Research, 31, 1573-1579.

https://doi.org/10.1016/S0008-8846(01)00602-0

[7] Bullard, J.W. (2008) A Determination of Hydration Mechanisms for Tricalcium Silicate Using a Kinetic Cellular Automaton Model. J. Am. Ceram. Soc., 91, 2088-2097. https://doi.org/10.1111/j.1551-2916.2008.02419.x

[8] Bishnoi, S. and Scrivener, K.L. (2009) $\mu$ ic: A New Platform for Modelling the Hydration of Cements. Cement and Concrete Research, 39, 266-274.

https://doi.org/10.1016/j.cemconres.2008.12.002

[9] Thomas, J.J., Biernacki, J.J., Bullard, J.W., Bishnoi, S., Dolado, J.S., Scherer, G.W. and Luttge (2011) Modeling and Simulation of Cement Hydration Kinetics and Microstructure Development. Cement and Concrete Research, 41, 1257-1278. https://doi.org/10.1016/j.cemconres.2010.10.004

[10] Scherer, G.W., Zhang, J., Quintanilla, J.A. and Torquato, S. (2012) Hydration and Percolation at the Setting Point. Cement and Concrete Research, 42, 665-672. https://doi.org/10.1016/j.cemconres.2012.02.003

[11] Scherer, G.W., Zhang, J. and Thomas, J.J. (2012) Nucleation and Growth Models for Hydration of Cement. Cement and Concrete Research, 42, 982-993.

https://doi.org/10.1016/j.cemconres.2012.03.019

[12] de Korte, A.C.J. and Brouwers, H.J.H. (2013) Random Packing of Digitized Particle. Powder Technology, 233, 319-324. https://doi.org/10.1016/j.powtec.2012.09.015

[13] Feylessoufi, A. (2014) Le Nanocristallite Cimentaire. In: Lourtios, J.-M., et al., eds., Chapter $4 B$ Nanosciences et Nanotechnologies, évolution ou révolution, Paris, Belin, 191-205.

[14] Feylessoufi, A. (2016) Nanocrystallites in Cement: What Future after Two Thousands Years? In: Lourtios, J.-M., et al., eds., Chapter 7 Nanosciences and Nanothechnology, Springer, Switzerland, 183-198. 